\title{
TRADITIONAL PROCUREMENT Vs PUBLIC, PRIVATE PARTNERSHIP MODEL - A Solution Based Approach for Indian Sub Continent
}

\author{
Dr. Krishnan Sampath \\ 1President, CESL Limited, Tamilnadu, eandtcpl@gmail.com; \\ and
}

\section{Prof.Panchanatham Natarajan}

${ }^{2}$ Vice-Chancellor, Tamilnadu Teacher Education University, Chennai, Tamilnadu, India; panchanatham@gmail.com

\begin{abstract}
Infrastructure development creates enough economic activities and development that have direct impact on socio economic development and overall national development. However, the role of traditional procurement / government spending on this sector has been under tremendous stress due to limited availability of resources. Public and private model and $100 \%$ private investments have been in vogue since couple of decades. The empirical government data projects a negligible or poor contribution of private sector, for various reasons though. The infrastructure gaps are still large and bridging those gaps will require tackling several problems, in terms of additional. This paper evaluates the current investment scenario and provide for radical changes in thought process and approach towards improving private participation in nation infrastructure building. One such approach is creating a national stock exchange for all private and public infrastructure investments and tagging this segment with organised industry profile. A CaaS (Construction As A Service) concept is being proposed to effectively utilise the limited resources and to avoid overlapping wasteful expenditures through pooling and shared services and on demand model. While it is not imperative to impress upon the establishment and public alike about the importance of private participation in infrastructure investments, it is order of the day to convince them about the real return on investments that they would commit. Similarly, bringing in public at large to participate in investing in infrastructure, a radical change will happen for good and the nation progress.
\end{abstract}

Keywords: Traditional procurement, Private and public participation, Investment, Infrastructure, Transparency, Contract, Construction, Social and Society

\section{Objective}

The objective of this paper is to dissect the investment portfolio of three different models of infrastructure investments viz., Traditional procurement aka Government / public funds, entirely private funds and a public-private partnership (PPP) model, with a specific focus on PPP model.

The purpose of the empirical study is to lay bare structure and recommend sustainable guidelines for growth in private investment and their participation in nation building for high quality infrastructure driven economic development.
Vol. 11 Issue 1 Jan. 2021 PP DOI:
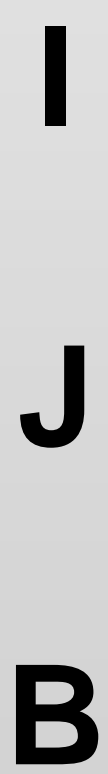

A
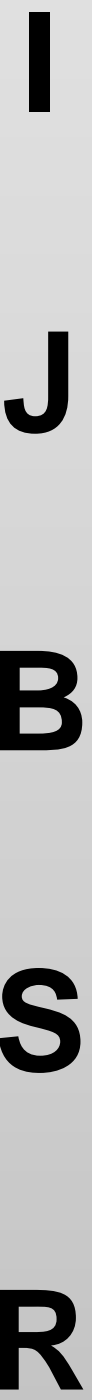